\title{
PERSISTENCE IN INTERNATIONAL INFLATION RATES ${ }^{1}$
}

\author{
Christopher F. Baum \\ Department of Economics \\ Boston College \\ Chestnut Hill, MA 02467 USA \\ baum@bc.edu \\ John T. Barkoulas \\ Department of Economics and Finance \\ Louisiana Tech University \\ Ruston, LA 71272 USA \\ barkoulas@hotmail.com \\ Mustafa Caglayan \\ Department of Economics \\ Koç University \\ Istanbul, Turkey \\ mcaglayan@ku.edu.tr \\ Running head: Persistence in International \\ Inflation Rates \\ JEL: E31, E32, C22

\footnotetext{
1 We are grateful to Pedro de Lima and Uwe Hassler for providing their software and assistance in its modification. We acknowledge the helpful comments of two anonymous reviewers and a coeditor of this journal. The standard disclaimer applies. Please address correspondence to the first author.
} 


\begin{abstract}
We test for fractional dynamics in CPI-based inflation rates for twenty-seven countries and WPI-based inflation rates for twenty-two countries. The fractional differencing parameter is estimated using semiparametric and approximate maximum likelihood methods. Significant evidence of fractional dynamics with long-memory features is found in both CPI- and WPI-based inflation rates for industrial as well as developing countries. Implications of the findings are considered and sources of long memory are hypothesized.
\end{abstract}




\section{Introduction}

An understanding of the dynamic properties of the inflation rate is essential to policymakers' ability to keep inflation in check. Despite extensive research following the pioneering work of Nelson and Plosser (1982), disagreement remains in the literature on a key question: does the postwar inflation rate possess a unit root? Although there is considerable evidence in support of a unit root (e.g. Barsky 1987; MacDonald and Murphy 1989; Ball and Cecchetti 1990; Wickens and Tzavalis 1992; and Kim 1993), Rose (1988) provided evidence of stationarity in inflation rates. Mixed evidence has been provided by Kirchgassner and Wolters (1993). Brunner and Hess (1993) argue that the inflation rate was stationary before the 1960s, but that it possesses a unit root since that time.

A potential resolution to this debate should be of more than academic interest, as nonstationarity in the inflation process would have consequences for central banks' ratification of inflationary shocks and would affect macroeconomic policymakers' response to external pressures. An explanation for this conflicting evidence was recently provided by modeling inflation rates as fractionally integrated processes. Using the fractional differencing model developed by Granger and Joyeux (1980), Hosking (1981), and Geweke and Porter-Hudak (1983), Baillie, Chung, and 
Tieslau (1996) find strong evidence of long memory in the inflation rates for the Group of Seven (G7) countries (with the exception of Japan) and those of three high inflation countries: Argentina, Brazil, and Israel. Similar evidence of strong long-term persistence in the inflation rates of the U.S., U.K., Germany, France, and Italy is also provided by Hassler and Wolters (1995). Delgado and Robinson (1994) find evidence of persistent dependence in the Spanish inflation rate. The interpretation of this evidence suggests that inflation rates are mean-reverting processes, so that an inflationary shock will persist, but will eventually dissipate.

Since modeling the inflation rate as a fractionally integrated process appears to improve our understanding of inflationary dynamics, this study extends the existing long-memory evidence on inflation rates along two dimensions. First, it performs long-memory analysis on inflation rates for a number of countries not previously considered, both industrial and developing, in order to provide more comprehensive evidence regarding the low-frequency properties of international inflation rates and to determine whether long memory is a common feature. Second, the paper investigates the existence of long-memory properties of inflation rates based not only on the consumer price index (CPI), as exclusively considered in the literature, but also on the wholesale price index (WPI). The WPI is not as heavily influenced by the prices of nontraded goods as is the CPI, and it may therefore serve as a better indicator in tests 
of the international arbitrage relationship between traded goods prices and exchange rates. WPI-based measures have been used extensively in empirical applications such as tests of purchasing power parity, empirical trade models, models of relative price responses, and models of the international transmission of inflation (e.g. Diebold, Husted and Rush 1991; Rogers and Wang 1993; Fukuda, Teruyama and Toda 1991). Therefore, we investigate and analyze the long-memory characteristics of WPI-based inflation rates, as well as their CPI-based counterparts, for developing as well as industrial countries.

Our data set consists of monthly CPI-based inflation rates for 27 countries and WPI-based inflation rates for 22 countries and covers the period 1971:1 to 1995:12. We estimate the fractional differencing parameter using both semiparametric (spectral regression and Gaussian semiparametric) and approximate maximum likelihood techniques. Evidence in the literature for long memory in major countries' CPI-based inflation rates is shown to generalize to both CPI- and WPI-based inflation rates for other industrial as well as developing countries. This evidence implies that policymakers may use fractionally integrated models of inflation to good advantage in modeling and forecasting the path of inflation rates. As potential sources of fractional dynamics in inflation rates, we hypothesize Granger's (1980) aggregation argument and the established presence of long memory in the growth rate of money.

The remainder of the paper is constructed as follows. Section 2 
presents the methods employed for the estimation of the fractional differencing parameter. Data and empirical results are discussed in section 3 . We conclude in section 4 with a summary and implications of our results.

\section{Fractional Integration Estimation Methods}

The model of an autoregressive fractionally integrated moving average process of order $(p, d, q)$, denoted by $\operatorname{ARFIMA}(p, d, q)$, with mean $\mu$, may be written using operator notation as

$$
\Phi(L)(1-L)^{d}\left(y_{t}-\mu\right)=\Theta(L) u_{t}, u_{t} \sim i . i . d .\left(0, \sigma_{u}^{2}\right)
$$

where $L$ is the backward-shift operator, $\Phi(L)=1-\phi_{1} L-\ldots-\phi_{p} L^{p}$, $\Theta(L)=1+\vartheta_{1} L+\ldots+\vartheta_{q} L^{q}$, and $(1-L)^{d}$ is the fractional differencing operator defined by

$$
(1-L)^{d}=\sum_{k=0}^{\infty} \frac{\Gamma(k-d) L^{k}}{\Gamma(-d) \Gamma(k+1)}
$$

with $\Gamma(\cdot)$ denoting the gamma function. The parameter $d$ is allowed to assume any real value. The arbitrary restriction of $d$ to integer values gives rise to the standard autoregressive integrated moving average (ARIMA) model. The stochastic process $y_{t}$ is both stationary and invertible if all roots of $\Phi(L)$ and $\Theta(L)$ lie outside the unit circle and $|d|<0.5$. The process is nonstationary for $d \geq 0.5$, as 
it possesses infinite variance, i.e. see Granger and Joyeux (1980). Assuming that $d \in(0,0.5)$ and $d \neq 0$, Hosking (1981) showed that the correlation function, $\rho(\cdot)$, of an ARFIMA process is proportional to $k^{2 d-1}$ as $k \rightarrow \infty$. Consequently, the autocorrelations of the ARFIMA process decay hyperbolically to zero as $k \rightarrow \infty$ in contrast to the faster, geometric decay of a stationary ARMA process. For $d \in(0,0.5), \sum_{j=-n}^{n}|\rho(j)|$ diverges as $n \rightarrow \infty$, and the ARFIMA process is said to exhibit long memory, or long-range positive dependence. The process is said to exhibit intermediate memory (anti-persistence), or long-range negative dependence, for $d \in(-0.5,0)$. The process exhibits short memory for $d=0$, corresponding to stationary and invertible ARMA modeling. For $d \in[0.5,1)$ the process is mean reverting, even though it is not covariance stationary, as there is no long-run impact of an innovation on future values of the process.

The fractional differencing parameter is estimated using two semiparametric methods, the spectral regression and Gaussian semiparametric approaches, and the frequency-domain approximate maximum likelihood method. A brief description of these estimation methods follows.

\section{The Spectral Regression Method}

Geweke and Porter-Hudak (1983) suggest a semiparametric procedure to obtain an estimate of the fractional differencing parameter $d$ based on the slope of the spectral density function around the angular frequency 
$\xi=0$

The spectral regression is defined by

$$
\ln \left\{I\left(\xi_{\lambda}\right)\right\}=\beta_{0}+\beta_{1} \ln \left\{4 \sin ^{2}\left(\frac{\xi_{\lambda}}{2}\right)\right\}+\eta_{\lambda}, \lambda=1, \ldots, \nu
$$

where $I\left(\xi_{\lambda}\right)$ is the periodogram of the time series at the Fourier frequencies of the sample $\xi_{\lambda}=\frac{2 \pi \lambda}{T}\left(\lambda=1, \ldots, \frac{(T-1)}{2}\right), T$ is the number of observations, and $\nu=g(T)<<T$ is the number of Fourier frequencies included in the spectral regression.

Assuming that $\lim _{T \rightarrow \infty} g(T)=\infty, \lim _{T \rightarrow \infty}\left\{\frac{g(T)}{T}\right\}=0$, and $\lim _{T \rightarrow \infty}\left\{\frac{\ln (T)^{2}}{g(T)}\right\}=$ 0 , the negative of the OLS estimate of the slope coefficient in (2) provides an estimate of $d$. Geweke and Porter-Hudak (1983) prove consistency and asymptotic normality for $d<0$, while Robinson (1995a) proves consistency and asymptotic normality for $d \in(0,0.5)$ in the case of Gaussian ARMA innovations in (1).

Ooms and Hassler (1997) show that the spectral regression will contain singularities due to prior deseasonalization of the series through standard seasonal adjustment techniques (utilizing seasonal dummy variables). The singularity problem arises because the periodogram $I\left(\xi_{\lambda}\right)$ of a seasonally adjusted series is zero (and does not possess a finite logarithm) at frequencies $\xi_{\lambda}=\frac{2 \pi \lambda}{s}, \lambda=0, \ldots, s$, where $s$ is the number of observations per year. In order to correct for this problem, Ooms and Hassler suggest extending the original data series to full calendar years via 'zero padding' and then omitting the periodogram ordinates corresponding to 
seasonal frequencies when estimating the log-periodogram regression in (2). We refer to this method, which yields more stable and reliable estimates than those generated by the standard spectral regression approach, as the adjusted spectral regression method.

\section{The Gaussian Semiparametric Method}

Robinson (1995b) proposes a Gaussian semiparametric estimator, GS hereafter, of the self-similarity parameter $H$, which is not defined in closed form. It is assumed that the spectral density of the time series, denoted by $f(\cdot)$, behaves as

$$
f(\xi) \sim G \xi^{1-2 H} \text { as } \xi \rightarrow 0^{+}
$$

for $\mathrm{G} \in(0, \infty)$ and $H \in(0,1)$. The self-similarity parameter $H$ relates to the long-memory parameter $d$ by $H=d+\frac{1}{2}$. The estimate for $H$, denoted $\widehat{H}$, is obtained through minimization of the function

$$
R(H)=\ln \widehat{G}(H)-(2 H-1) \frac{1}{\nu} \sum_{\lambda=1}^{\nu} \ln \xi_{\lambda}
$$

with respect to $H$, where $\widehat{G}(H)=\frac{1}{\nu} \sum_{\lambda=1}^{\nu} \xi_{\lambda}^{2 H-1} I\left(\xi_{\lambda}\right)$. The discrete averaging is carried out over the neighborhood of zero frequency and, in asymptotic theory, $\nu$ is assumed to tend to infinity much more slowly than $T$. The GS estimator has several advantages over the spectral regression estimator and its variants. It is consistent under mild conditions and, under somewhat stronger conditions, it is asymptotically normal and more effi- 
cient. Gaussianity is nowhere assumed in the asymptotic theory. The GS estimator is $\nu^{\frac{1}{2}}$-consistent with a variance of the limiting distribution free of nuisance parameters and equal to $\frac{1}{4 \nu}$.

\section{The Approximate Maximum Likelihood Method}

Fox and Taqqu (1986) propose a frequency-domain approximate maximum likelihood (ML) method to simultaneously estimate both the short-memory and long-memory parameters of an ARFIMA model. It approximates the Gaussian likelihood in the frequency domain, which amounts to minimizing the logarithm of the spectral likelihood function

$$
L(\gamma)=\frac{2 \pi}{T} \sum_{\lambda=1}^{\frac{T}{2}}\left\{\ln f\left(\xi_{\lambda}, \gamma\right)+\frac{I\left(\xi_{\lambda}\right)}{f\left(\xi_{\lambda}, \gamma\right)}\right\}
$$

with respect to the parameter vector $\gamma=\left(d, \varphi_{1}, \ldots, \varphi_{p}, \vartheta_{1}, \ldots, \vartheta_{q}\right)$, where $I\left(\xi_{\lambda}\right)$ is defined as above and $f\left(\xi_{\lambda}, \gamma\right)$ is the spectrum of the ARFIMA model being estimated. The resulting ML estimates of $\gamma$ are consistent and asymptotically normal. Cheung and Diebold (1994) suggest that the frequency-domain approximate ML estimator compares favorably, in terms of its finite-sample properties, to the much more computationally arduous time-domain exact ML estimator proposed by Sowell (1992) in the case that the mean of the process is unknown. 


\section{Data and Empirical Estimates}

\section{Data}

We perform the analysis on CPI-based inflation rates for 27 countries and WPI-based inflation rates for 22 countries. All data series are seasonally unadjusted monthly observations beginning in 1971:1, roughly corresponding to the end of the Bretton Woods exchange rate regime, and ending in 1995:12 (for a total of 300 observations) and were obtained from the IMF's International Financial Statistics database. For the CPIbased inflation rate series, our sample countries are the U.S., Canada, Germany, U.K., France, Italy, Japan, Austria, Belgium, Denmark, Mexico, Netherlands, Norway, Sweden, Switzerland, Luxemburg, Finland, Greece, Portugal, Spain, South Africa, Turkey, India, Indonesia, South Korea, Philippines, and Pakistan. For the WPI-based inflation rate series, our sample excludes France, Italy, Belgium, Switzerland, Luxemburg, Portugal, and Turkey, for which WPI series are not available, and adds Australia and Ireland, for which only WPI series are available. Unless otherwise indicated, the estimation methods are applied to seasonally adjusted series derived from the application of monthly seasonal dummies. There is evidence of seasonality for all series except for the CPI-based inflation rate series for Mexico and the WPI-based inflation rate series 
for the U.S., Japan, Finland, Australia, South Africa, and Indonesia. ${ }^{1}$

\section{Empirical Estimates for CPI-based Series}

The evidence for the CPI-based inflation rates is presented first, followed by that for the WPI-based inflation rate series. The tables classify countries into three categories: G7 countries, other industrial countries, and developing countries.

In estimating the fractional exponent using periodogram-based methods, a choice has to be made with respect to the number of low-frequency periodogram ordinates used. Improper inclusion of medium- or high-frequency periodogram ordinates will bias the estimate of $d$; at the same time too small an estimation sample will increase the sampling variability of the estimates. To evaluate the sensitivity of our results to the choice of estimation sample size $\nu$, we report fractional differencing estimates for $\nu=20,30,40,50$, and 60. We impose the known theoretical variance of the regression error $\frac{\pi^{2}}{6}$ in the construction of the standard error for the spectral regression $d$ estimate.

Table 1 presents the spectral regression estimates of the fractional differencing parameter $d$ for the CPI-based inflation rates. ${ }^{2}$ The $d$ estimates for the inflation rates for the G7, other industrial, and developing countries are significantly positive. They generally decline with the size of the spectral regression but they stabilize and remain significantly positive (with the exception of Switzerland). ${ }^{3,4}$ Thus the 
presence of long-memory features in the CPI-based inflation rates for major industrial countries reported by Baillie, Chung and Tieslau. (1996) and Hassler and Wolters (1995) generalizes to other industrial countries as well as developing countries.

Table 2 reports the GS results for the CPI-based inflation rate series. ${ }^{5}$ The GS fractional differencing estimates are generally similar in magnitude to the corresponding spectral regression estimates. Strong evidence of persistent dependence is obtained for all CPI-based inflation rates, with the possible exception of Indonesia for which the long-memory evidence is unstable across estimation sample sizes.

Table 3 reports the frequency-domain approximate ML estimates for the CPI-based inflation rate series. Contrary to the spectral regression and Gaussian semiparametric methods, the approximate ML method simultaneously estimates both the short-memory and long-memory parameters of the model. For simple models, such as fractional Gaussian noise, parameter estimates may be easily obtained. However, the computational problems associated with estimation of the model become more serious for higher-order shortmemory (ARMA) structures (e.g. tradeoffs between the value of the longmemory parameter and those of the ARMA parameters, as well as possible stationarity and invertibility problems with the AR and MA polynomials, respectively). To minimize the effects of an overparameterized shortmemory structure and preserve parsimony, we arrive at the final ARFIMA specification via the following strategy. We allow for a short-memory 
structure up to AR(2), use the Schwarz information criterion (SIC) to choose the best model, test the statistical significance of the AR coefficients, and ensure that the stationarity condition is met for the resulting AR polynomial. ${ }^{6}$ As Table 3 reports, the ARFIMA specifications selected result in fractional-differencing parameter estimates broadly consistent with the semiparametric estimates. Significant evidence of long memory is obtained for all CPI-based inflation rate series, thus reinforcing the robustness of the evidence over alternative estimation methods.

\section{Empirical Estimates for WPI-based Series}

Spectral regression estimates of the fractional differencing parameter for the WPI-based inflation rate series are reported in Table 4. The spectral regression estimates are significantly greater than zero for all WPI-based inflation rate series except for Austria, the Netherlands, and Pakistan. This long-memory evidence is robust with respect to the number of harmonic ordinates used in the spectral regression. As in the case of the CPI-based series, long-term persistence appears to characterize the dynamic behavior of WPI-based inflation rate series for both industrial and developing countries.

Strong evidence of persistence in the stochastic behavior of the WPIbased inflation rates is also provided by the GS results presented in Table 5. The GS fractional differencing estimates are broadly consistent 
with the corresponding spectral regression estimates. Evidence in support of long-memory dynamics is obtained for all WPI-based inflation rate series. For Austria, the Netherlands and Pakistan, for which the spectral regression method did not find evidence of long-term persistence, the GS method does find such evidence although it is rather mild for the Netherlands and Pakistan.

Approximate ML estimates of the long-memory parameter for the WPIbased inflation rate series, which are reported in Table 6 , confirm the evidence obtained from the semiparametric estimation methods. There is evidence of fractional dynamics with long-memory features in the series for all countries except, possibly, for Pakistan, for which the long-memory parameter is only significant at the ten per cent level.

For several of the inflation rate series, the long-memory estimates are in the vicinity of the stationarity threshold of 0.5 . In the majority of cases, the long-memory estimates are below 0.5 for both CPI- and WPI-based inflation rates, implying stationarity of the inflation rate series. Long memory indicates that the inflation rate exhibits strong positive dependence between distant observations. More specifically, positive persistent dependence suggests that countries experience long periods of generally upward-trending inflation rates as well as long periods of generally downward-trending inflation rates. The behavior of inflation rates is characterized by long yet nonperiodic cycles. In the time domain, a shock to the inflation rate series persists but it 
eventually dissipates since the series is mean reverting. ${ }^{7,8}$

The robustness of the long-memory evidence across alternative estimation methods for most of these inflation series suggests that persistence is a common feature of these data, and that ARMA representations will generally be inadequate to capture their dynamic properties. ${ }^{9}$ Additionally, the joint process of inflation rate series is no longer adequately characterized by a linear vector autoregression (VAR); the nonlinear relations arising in this context deserve further scrutiny. Care must be exercised in estimating any regression in which two or more fractionally integrated processes appear, as they would in virtually any model containing two or more of the series studied here. If their orders of integration sum to greater than 0.5, 'spurious regression' effects might appear (Tsay 1995).

\section{Conclusions and Implications}

This paper tests for the existence of long memory, or persistence, in international inflation rates for a number of industrial and developing countries using semiparametric and maximum likelihood estimation methods. The analysis employs both CPI-based and WPI-based inflation rates for twenty-seven and twenty-two countries, respectively, over the postBretton Woods (1971-1995) period. Extending previous research on CPIbased inflation rates for major industrial countries, we provide evidence 
that long memory in the CPI-based inflation rate is a general phenomenon for other industrial countries as well as for a number of developing countries. In addition, we provide the first evidence that WPI-based inflation rates also exhibit long-memory features for both developed and developing economies. This evidence is substantial and robust in support of persistence in both CPI- and WPI-based inflation rates. In general, the estimate of the fractional-differencing parameter for either series is similar when we apply adjusted spectral regression, Gaussian semiparametric, and approximate maximum likelihood techniques. In that respect, we demonstrate that an ARFIMA model is an appropriate representation of the stochastic behavior of international inflation rates and that long memory is a common feature for the countries studied. Contrary to the popular belief arising from unit-root tests in many empirical applications, inflation rates, however defined and for the vast majority of countries, do not possess a unit root.

It should be noted that the ability to adequately represent inflation series as ARFIMA processes, which allow for richer dynamics in the stochastic behavior of the series, should be of particular interest to policymakers. Policymakers utilizing the properties of ARFIMA representations may be able to make more accurate short- and long-term forecasts of the future path of inflation rates, which are instrumental to the successful implementation of deflationary policies based on inflation targeting. Since forecasting performance improves significantly when 
the correct stochastic process is utilized for the series under scrutiny, generating forecasts of CPI-based and WPI-based inflation rates using ARFIMA models should be a fruitful approach. However, performance of forecasting experiments is beyond the scope of this paper and warrants further research.

A likely explanation of the significant persistence in these inflation rate series is the aggregation argument put forth by Granger (1980), which states that persistence can arise from the aggregation of constituent processes, each of which has short memory. ${ }^{10,11}$ Granger and Ding (1996) show that the long-memory property could also arise from time-varying coefficient models or nonlinear models. An alternative conjecture is that inflation inherits the long-memory property from money growth. Porter-Hudak (1990) and Barkoulas, Baum, and Caglayan (1998) have shown that the U.S. monetary aggregates exhibit the long-memory property, which will be transmitted to inflation, given the dependence of long-run inflation on the growth rate of money. Further analysis of the monetary policy mechanism that gives rise to this persistence in the monetary aggregates--and thus in inflation and other macroeconomic variables--will be one focus of our future research. 


\section{References}

Baillie, Richard T., Ching-Fan Chung, and Margie A. Tieslau. 1996. Analysing inflation by the fractionally integrated ARFIMA-GARCH model. Journal of Applied Econometrics, 11:23-40.

Ball, Laurence, and Stephen G. Cecchetti. 1990. Inflation and uncertainty at short and long horizons. Brookings Papers on Economic Activity. 215-254.

Barkoulas, John T., Christopher F. Baum, and Mustafa Caglayan. 1998. Fractional monetary dynamics. Applied Economics. In press.

Barsky, Robert B. 1987. The Fisher hypothesis and the forecastibility and persistence of inflation. Journal of Monetary Economics. 19:3-24.

Brunner, Allan D., and Gregory D. Hess. 1993. Are higher levels of inflation less predictable? A state-dependent conditional heteroscedasticity approach. Journal of Business and Economic Statistics. $11(2): 187-197$.

Canzoneri, Matthew, Robert Cumby, and Behzad Diba. 1996. Relative labor productivity and the real exchange rate in the long run: Evidence for a panel of OECD countries. NBER Working Paper No. 5676.

Cheung, Yin-Wong, and Francis X. Diebold. 1994. On the maximumlikelihood estimation of the differencing parameter of fractionally integrated noise with unknown mean. Journal of Econometrics. 62:301316.

Delgado, Miguel A., and Peter M. Robinson. 1994. New methods for the 
analysis of long-memory time-series: application to Spanish inflation. Journal of Forecasting. 13:97-107.

Diebold, Francis X., Steven Husted, and Mark Rush. 1991. Real exchange rates under the gold standard. Journal of Political Economy. $99: 1057-1072$

Fox, Robert, and Murad S. Taqqu. 1986. Large sample properties of parameter estimates for strongly dependent gaussian time-series. Annals of Statistics. 14:517-532.

Fukuda, Shin-ichi, Hiroshi Teruyama, and Hiro Y. Toda. 1991. Inflation and price-wage dispersions in Japan. Journal of the Japanese and International Economy. 5:160-188.

Geweke, John, and Susan Porter-Hudak. 1983. The estimation and application of long memory time series models. Journal of Time Series Analysis. $4: 221-238$.

Granger, Clive W. J. 1980. Long memory relationships and the aggregation of dynamic models. Journal of Econometrics. 25:227-238.

Granger, Clive W. J., and Roselyne Joyeux. 1980. An introduction to long-memory time series models and fractional differencing. Journal of Time Series Analysis. 1:15-39.

Granger, Clive W.J., and Zhuanxin Ding. 1996. Varieties of long memory models. Journal of Econometrics. 73:61-77.

Hassler, Uwe, and Jurgen Wolters. 1995. Long memory in inflation rates: International evidence. Journal of Business and Economic 
Statistics . 13:37-45.

Hosking, J. R. M. 1981. Fractional differencing. Biometrika. 68:165176.

Kim, Chang-Jin. 1993. Unobserved-component time series models with Markov-switching heteroscedasticity: Changes in regime and the link between inflation rates and inflation uncertainty. Journal of Business and Economic Statistics. 11:341-349.

Kirchgassner, Gebhard, and Jurgen Wolters. 1993. Are real interest rates stable? An international comparison. In Studies in Applied Econometrics, edited by H. Schneeweiss and K. F. Zimmermann. Heidelberg:Physica-Verlag, pp. 214-238.

Kwiatkowski, Denis, Peter C. B. Phillips, Peter Schmidt, and Y. Shin. 1992. Testing the null hypothesis of stationarity against the alternative of a unit root: How sure are we that economic time series have a unit root? Journal of Econometrics. 54:159-178.

MacDonald, Ronald, and P. D. Murphy. 1989. Testing for the long run relationship between nominal interest rates and inflation using cointegration techniques. Applied Economics. 21:439-447.

Nelson, Charles R., and Charles I. Plosser. 1982. Trends and random walks in macroeconomic time series: Some evidence and implications. Journal of Monetary Economics. 10(2):139-162.

Oh, Keun-Yeob. 1996. Purchasing power parity and unit root tests using panel data. Journal of International Money and Finance. 15(3):405- 
418.

Doms, Marius 1997. Long memory and seasonality in U.S. consumer price inflation: An empirical investigation at varying levels of aggregation. Unpublished paper, Econometric Institute, University of Rotterdam.

Ooms, Marius, and Uwe Hassler. 1997. A note on the effect of seasonal dummies on the periodogram regression. Economics Letters. 56:135141.

Pedroni, Peter 1995. Panel cointegration: asymptotic and finite sample properties of pooled time series tests with an application to the PPP hypothesis. Unpublished paper 95-013, Department of Economics, Indiana University.

Phillips, Peter C. B., and Pierre Perron. 1988. Testing for a unit root in time series regression. Biometrika. 75:335-346.

Porter-Hudak, Susan. 1990. An application of the seasonal fractionally differenced model to the monetary aggregates. Journal of the American Statistical Association. 85:338-344.

Robinson, Peter. 1995a. Log-periodogram regression of time series with long range dependence. Annals of Statistics. 23:1048-1072.

Robinson, Peter. 1995b. Gaussian semiparametric estimation of long range dependence. Annals of Statistics. 23:1630-1661.

Rogers, John H., and P. Wang. 1993. Sources of fluctuations in relative prices: Evidence from high inflation countries. Review of Economics and Statistics. 75(4):589-605. 
Rose, Andrew K. 1988. Is the real interest rate stable? Journal of Finance. 43:1095-1112.

Sowell, Fallaw. 1992. Maximum likelihood estimation of stationary univariate fractionally-integrated time-series models. Journal of Econometrics. 53:165-188.

Tsay, Wen-Jen. 1995. Spurious effects concerned with fractional processes. Ph.D. dissertation, Michigan State University, East Lansing, MI .

Wickens, Michael, and Elias Tzavalis. 1992. Forecasting inflation from the term structure: A cointegration approach. Unpublished paper 13-92, London Business School, Centre of Economic Research. 


\section{Notes}

${ }^{1}$ For those inflation rate series in which no seasonality was detected, the spectral regression method (Geweke and Porter-Hudak 1983) is applied. For those series exhibiting seasonality, the adjusted spectral regression method of Ooms and Hassler (1997) is applied to the original series, since that method utilizes only non-seasonal frequencies in the logperiodogram regression.

${ }^{2}$ We also applied the Phillips-Perron (PP, 1988) and Kwiatkowski et al. (KPSS, 1992) unit-root tests to both CPI- and WPI-based inflation rate series. The combined use of these unit-root tests offers contradictory inference regarding the low-frequency behavior of the vast majority of the inflation rate series, thus providing motivation for testing for fractional roots in the series. The long-memory evidence to follow reconciles the conflicting inference derived from the PP and KPSS tests. To conserve space, these results are not reported but they are available upon request.

${ }^{3}$ For small spectral regression sample sizes, especially for $\nu=20$, the variance of the spectral regression estimator is rather large and we do not therefore rely on the corresponding estimates in interpreting our evidence. We proceed similarly for the evidence obtained from the GS method.

${ }^{4}$ It must be noted that in most cases the spectral regression $d$ estimates lie within the $95 \%$ confidence intervals $(d(\nu) \pm 2 \mathrm{SE})$ around $d(\nu)$ 
for $\nu=20,30,40,50,60$, where $S E$ denotes the corresponding estimated standard error for the $d$ estimates across the sample sizes considered. The same holds true for the GS estimates of the long-memory parameter.

${ }^{5}$ The GS and approximate ML estimation methods are applied to the seasonally adjusted series if seasonality is detected. These methods are not subject to the Ooms-Hassler critique discussed above.

${ }^{6}$ We allowed for short-memory dynamics up to ARMA $(2,2)$ but in several cases parameter redundancies, nonstationarity of the AR polynomial, or noninvertibility of the MA polynomial resulted. After some experimentation, we opted for a short-memory structure up to AR(2). The reported long-memory evidence (estimates of $d$ ) is not materially sensitive to the specific AR (or ARMA) structure considered.

${ }^{7}$ The cumulative impulse response at an infinite horizon of future values of the inflation rate series to a unit innovation is zero for $0<d<1$.

${ }^{8}$ In the frequency domain, long memory is characterized by an unbounded spectral density at zero frequency.

${ }^{9}$ The integration properties of cross-country data have been tested, in recent literature, with panel data methods (e.g. Pedroni 1995; Canzoneri, Cumby and Diba 1996; Oh 1996). These pooling methods allow stronger inferences to be drawn from the data. In our case, the robust evidence available from univariate tests would not be qualitatively affected by multivariate test findings . 


\begin{abstract}
${ }^{10}$ Granger (1980) showed that if a time series $y_{t}$ is the sum of many independent AR(1) processes which have equal variances and whose autoregressive parameters are drawn independently from a beta distribution, then it has the same correlation structure as an ARFIMA process with an appropriately defined fractional differencing parameter.

${ }^{11}$ Ooms (1997), analyzing disaggregated components of the U.S. CPIbased inflation rate, finds that Granger's aggregation hypothesis may be important in explaining long memory.
\end{abstract}


Table 1: Spectral Regression Estimates of the

Fractional-Differencing Parameter $d$ for CPI-based Inflation Rates

\begin{tabular}{|c|c|c|c|c|c|}
\hline $\begin{array}{l}\text { Inflation Series } \\
\text { G7 Countries }\end{array}$ & $\begin{array}{l}\text { Number of } \\
\nu=20\end{array}$ & $\begin{array}{l}\text { Harmonic } \\
\nu=30\end{array}$ & $\begin{array}{c}\text { Ordinates } \\
\nu=40\end{array}$ & $\begin{array}{l}\text { in Spectral } \\
\nu=50\end{array}$ & $\begin{array}{c}\text { Regressior } \\
\nu=60\end{array}$ \\
\hline U.S. & 0.811 & 0.568 & 0.457 & 0.598 & 0.458 \\
\hline Canada & 0.711 & 0.585 & 0.547 & 0.523 & 0.474 \\
\hline Germany & 0.541 & 0.355 & 0.353 & 0.257 & 0.303 \\
\hline U.K. & 0.624 & 0.572 & 0.608 & 0.452 & 0.400 \\
\hline France & 0.661 & 0.535 & 0.460 & 0.390 & 0.390 \\
\hline Italy & 0.596 & 0.768 & 0.590 & 0.522 & 0.488 \\
\hline $\begin{array}{l}\text { Japan } \\
\text { Other Industrial Countries }\end{array}$ & 1.151 & 0.644 & 0.493 & 0.504 & 0.461 \\
\hline Austria & 0.602 & 0.226 & 0.304 & 0.196 & 0.212 \\
\hline Belgium & 0.661 & 0.437 & 0.513 & 0.420 & 0.374 \\
\hline Denmark & 0.480 & 0.347 & 0.282 & 0.209 & 0.260 \\
\hline Netherlands & 0.678 & 0.418 & 0.391 & 0.250 & 0.283 \\
\hline Norway & 0.860 & 0.547 & 0.400 & 0.343 & 0.357 \\
\hline Sweden & 0.565 & 0.374 & 0.292 & 0.188 & 0.240 \\
\hline Switzerland & 0.607 & 0.172 & 0.138 & 0.143 & 0.166 \\
\hline Luxemburg & 0.639 & 0.373 & 0.290 & 0.277 & 0.234 \\
\hline Finland & 0.989 & 0.616 & 0.576 & 0.373 & 0.301 \\
\hline Greece & 0.511 & 0.394 & 0.311 & 0.307 & 0.302 \\
\hline Portugal & 0.498 & 0.463 & 0.305 & 0.186 & 0.156 \\
\hline $\begin{array}{l}\text { Spain } \\
\text { Developing Countries }\end{array}$ & 0.692 & 0.308 & 0.151 & 0.229 & 0.133 \\
\hline South Africa & 0.640 & 0.228 & 0.176 & 0.156 & 0.147 \\
\hline Mexico & 0.516 & 0.314 & 0.278 & 0.167 & 0.137 \\
\hline Turkey & 0.627 & 0.460 & 0.358 & 0.297 & 0.306 \\
\hline India & 0.401 & 0.479 & 0.474 & 0.454 & 0.386 \\
\hline Indonesia & 0.728 & 0.459 & 0.251 & 0.197 & 0.289 \\
\hline South Korea & 0.542 & 0.532 & 0.442 & 0.382 & 0.397 \\
\hline Philippines & 0.419 & 0.569 & 0.451 & 0.311 & 0.321 \\
\hline Pakistan & 0.375 & 0.201 & 0.224 & 0.208 & 0.229 \\
\hline Standard Errors & 0.181 & 0.140 & 0.117 & 0.103 & 0.093 \\
\hline
\end{tabular}

Notes: The adjusted spectral regression method of Ooms and Hassler (1997) is applied to all series except Mexico, for which no seasonality is detected. The spectral regression method of 
Geweke and Porter-Hudak (1983) is used for Mexico. The number of harmonic ordinates indicate the

sample size of the spectral regression. The known theoretical error variance of $\frac{\pi^{2}}{6}$ is imposed in the calculation of the standard error of the fractional differencing parameter $d$. 
Table 2: Gaussian Semiparametric Estimates of the Fractional-Differencing Parameter $d$ for CPI-based Inflation Rates

\begin{tabular}{|c|c|c|c|c|c|}
\hline $\begin{array}{l}\text { Inflation Series } \\
\text { G7 Countries }\end{array}$ & $\nu=20$ & $\begin{array}{r}\text { Number } \\
\nu=30\end{array}$ & $\begin{array}{l}\text { f Harmoni } \\
\nu=40\end{array}$ & $\begin{array}{l}\text { Ordinates } \\
\nu=50\end{array}$ & $\nu=60$ \\
\hline U. S. & 0.840 & 0.584 & 0.528 & 0.539 & 0.510 \\
\hline Canada & 0.667 & 0.512 & 0.486 & 0.483 & 0.427 \\
\hline Germany & 0.643 & 0.497 & 0.444 & 0.432 & 0.397 \\
\hline U. K. & 0.513 & 0.469 & 0.521 & 0.373 & 0.362 \\
\hline France & 0.803 & 0.687 & 0.594 & 0.549 & 0.563 \\
\hline Italy & 0.647 & 0.696 & 0.488 & 0.503 & 0.470 \\
\hline $\begin{array}{l}\text { Japan } \\
\text { Other Industrial Countries }\end{array}$ & 0.939 & 0.565 & 0.487 & 0.461 & 0.415 \\
\hline Austria & 0.480 & 0.239 & 0.293 & 0.210 & 0.215 \\
\hline Belgium & 0.660 & 0.511 & 0.571 & 0.509 & 0.459 \\
\hline Denmark & 0.569 & 0.469 & 0.386 & 0.319 & 0.318 \\
\hline Netherlands & 0.811 & 0.500 & 0.458 & 0.353 & 0.297 \\
\hline Norway & 0.640 & 0.541 & 0.408 & 0.292 & 0.281 \\
\hline Sweden & 0.517 & 0.341 & 0.223 & 0.190 & 0.198 \\
\hline Switzerland & 0.645 & 0.243 & 0.236 & 0.222 & 0.224 \\
\hline Luxemburg & 0.581 & 0.438 & 0.380 & 0.364 & 0.361 \\
\hline Finland & 0.846 & 0.545 & 0.527 & 0.358 & 0.310 \\
\hline Greece & 0.538 & 0.426 & 0.399 & 0.354 & 0.336 \\
\hline Portugal & 0.551 & 0.579 & 0.404 & 0.315 & 0.304 \\
\hline $\begin{array}{l}\text { Spain } \\
\text { Developing Countries }\end{array}$ & 0.709 & 0.436 & 0.331 & 0.346 & 0.295 \\
\hline South Africa & 0.554 & 0.331 & 0.291 & 0.272 & 0.265 \\
\hline Mexico & 0.289 & 0.215 & 0.219 & 0.167 & 0.163 \\
\hline Turkey & 0586 & 0.409 & 0.337 & 0.314 & 0.278 \\
\hline India & 0.650 & 0.681 & 0.605 & 0.536 & 0.462 \\
\hline Indonesia & 0.286 & 0.095 & 0.096 & 0.125 & 0.203 \\
\hline South Korea & 0.454 & 0.488 & 0.364 & 0.337 & 0.326 \\
\hline Philippines & 0.338 & 0.766 & 0.549 & 0.388 & 0.340 \\
\hline Pakistan & 0.573 & 0.404 & 0.380 & 0.343 & 0.330 \\
\hline Standard Errors & 0.111 & 0.091 & 0.079 & 0.070 & 0.064 \\
\hline
\end{tabular}

Notes: The number of harmonic ordinates indicates the number of low-frequency periodogram ordinates used in the estimation. 
Table 3: Approximate Maximum Likelihood Estimates of the Fractional-Differencing Parameter $d$ for CPI-based Inflation Rates

\begin{tabular}{|c|c|c|c|c|}
\hline Inflation Series & $\begin{array}{l}A R(p) \\
\text { Order }\end{array}$ & $\begin{array}{c}\text { Long } \\
\text { Memory } \\
\text { Parameter } d\end{array}$ & $\begin{array}{l}\text { Standard } \\
\text { Error for } d \\
\text { Estimate }\end{array}$ & $\begin{array}{c}\text { t-statistic } \\
\text { for } \\
H_{0}: d=0\end{array}$ \\
\hline \multicolumn{5}{|l|}{ G7 Countries } \\
\hline U.S. & 0 & 0.497 & 0.046 & 10.779 \\
\hline Canada & 1 & 0.597 & 0.057 & 10.304 \\
\hline Germany & 2 & 0.475 & 0.075 & 6.327 \\
\hline U.K. & 2 & 0.632 & 0.081 & 7.791 \\
\hline France & 2 & 0.651 & 0.058 & 11.085 \\
\hline Italy & 2 & 0.638 & 0.080 & 7.940 \\
\hline Japan & 2 & 0.587 & 0.074 & 7.939 \\
\hline \multicolumn{5}{|c|}{ Other Industrial Countries } \\
\hline Austria & 2 & 0.387 & 0.067 & 5.753 \\
\hline Belgium & 1 & 0.552 & 0.057 & 9.599 \\
\hline Denmark & 2 & 0.441 & 0.061 & 7.156 \\
\hline Netherlands & 1 & 0.450 & 0.048 & 9.368 \\
\hline Norway & 0 & 0.387 & 0.043 & 8.888 \\
\hline Sweden & 2 & 0.355 & 0.069 & 5.166 \\
\hline Switzerland & 2 & 0.434 & 0.074 & 5.806 \\
\hline Luxemburg & 1 & 0.477 & 0.061 & 7.803 \\
\hline Finland & 1 & 0.464 & 0.048 & 9.620 \\
\hline Greece & 0 & 0.262 & 0.047 & 5.467 \\
\hline Portugal & 2 & 0.440 & 0.068 & 6.400 \\
\hline Spain & 2 & 0.479 & 0.058 & 8.229 \\
\hline \multicolumn{5}{|c|}{ Developing Countries } \\
\hline South Africa & 0 & 0.206 & 0.044 & 4.648 \\
\hline Mexico & 1 & 0.234 & 0.067 & 3.493 \\
\hline Turkey & 0 & 0.314 & 0.043 & 7.171 \\
\hline India & 0 & 0.417 & 0.049 & 8.514 \\
\hline Indonesia & 0 & 0.226 & 0.047 & 4.779 \\
\hline South Korea & 0 & 0.401 & 0.047 & 8.511 \\
\hline Philippines & 0 & 0.428 & 0.052 & 8.219 \\
\hline Pakistan & 0 & 0.265 & 0.049 & 5.408 \\
\hline
\end{tabular}


Table 4: Spectral Regression Estimates of the

Fractional-Differencing Parameter $d$ for WPI-based Inflation Rates

$\begin{array}{lccccc}\text { Inflation Series } & \nu=20 & \nu=30 & \nu=40 & \nu=50 & \nu=60 \\ \quad \text { G7 Countries } & & & & & \\ \text { U.S. } & 0.517 & 0.385 & 0.305 & 0.274 & 0.286 \\ \text { Canada } & 0.369 & 0.319 & 0.388 & 0.358 & 0.355 \\ \text { Germany } & 0.445 & 0.340 & 0.370 & 0.401 & 0.449 \\ \text { U.K. } & 0.713 & 0.621 & 0.646 & 0.513 & 0.471 \\ \text { Japan } & 0.474 & 0.467 & 0.545 & 0.496 & 0.467 \\ \quad \text { Other Industrial Countries } & & & & & \\ \text { Austria } & 0.157 & 0.207 & 0.263 & 0.186 & 0.198 \\ \text { Denmark } & 0.443 & 0.224 & 0.170 & 0.152 & 0.277 \\ \text { Netherlands } & 0.369 & 0.132 & 0.157 & 0.074 & 0.058 \\ \text { Norway } & 0.661 & 0.468 & 0.339 & 0.269 & 0.296 \\ \text { Sweden } & 0.338 & 0.250 & 0.253 & 0.269 & 0.370 \\ \text { Finland } & 0.901 & 0.705 & 0.542 & 0.394 & 0.465 \\ \text { Greece } & 0.251 & 0.275 & 0.362 & 0.293 & 0.342 \\ \text { Spain } & 0.510 & 0.293 & 0.308 & 0.162 & 0.181 \\ \text { Ireland } & 0.616 & 0.303 & 0.364 & 0.321 & 0.280 \\ \text { Australia } & 0.695 & 0.431 & 0.286 & 0.253 & 0.332 \\ \quad \text { Developing Countries } & & & & & \\ \text { South Africa } & 0.200 & 0.387 & 0.305 & 0.325 & 0.316 \\ \text { Mexico } & 0.908 & 0.852 & 0.639 & 0.597 & 0.493 \\ \text { India } & 0.354 & 0.406 & 0.293 & 0.291 & 0.250 \\ \text { Indonesia } & 0.312 & 0.261 & 0.167 & 0.217 & 0.265 \\ \text { South Korea } & 0.515 & 0.405 & 0.310 & 0.349 & 0.347 \\ \text { Philippines } & 0.486 & 0.456 & 0.427 & 0.395 & 0.355 \\ \text { Pakistan } & 0.349 & 0.211 & 0.104 & 0.150 & 0.069 \\ \text { Standard Errors } & 0.181 & 0.139 & 0.117 & 0.103 & 0.093\end{array}$

Number of Harmonic Ordinates in Spectral Regression
$\nu=20 \quad \nu=30 \quad \nu=40 \quad \nu=50 \quad \nu=60$

$\begin{array}{lllll}0.200 & 0.387 & 0.305 & 0.325 & 0.316\end{array}$

$\begin{array}{lllll}0.908 & 0.852 & 0.639 & 0.597 & 0.493\end{array}$

$\begin{array}{lllll}0.354 & 0.406 & 0.293 & 0.291 & 0.250\end{array}$

$\begin{array}{lllll}0.312 & 0.261 & 0.167 & 0.217 & 0.265\end{array}$

$\begin{array}{lllll}0.515 & 0.405 & 0.310 & 0.349 & 0.347\end{array}$

$\begin{array}{lllll}0.486 & 0.456 & 0.427 & 0.395 & 0.355\end{array}$

$\begin{array}{lllll}0.181 & 0.139 & 0.117 & 0.103 & 0.093\end{array}$

Notes: For the inflation series of the U.S., Japan, Finland, Australia, South Africa, and Indonesia, the spectral regression method of Geweke and Porter-Hudak (1983) is applied as no seasonality is present in these series. For the remaining series, seasonality is present and the spectral regression method of Ooms and Hassler (1997) is applied. The number of harmonic ordinates indicate the sample size of the spectral regression. The known theoretical error variance of $\frac{\pi^{2}}{6}$ is imposed in the calculation of the standard error of the fractional differencing parameter $d$. 
Table 5. Gaussian Semiparametric Estimates of the Fractional-Differencing Parameter $d$ for WPI-based Inflation Rates

\begin{tabular}{lccccc} 
& \multicolumn{5}{c}{ Number of Harmonic Ordinates } \\
Inflation Series & $\nu=20$ & $\nu=30$ & $\nu=40$ & $\nu=50$ & $\nu=60$ \\
$\quad$ G7 Countries & & & & & \\
U.S. & 0.310 & 0.292 & 0.267 & 0.213 & 0.227 \\
Canada & 0.812 & 0.551 & 0.545 & 0.531 & 0.494 \\
Germany & 0.636 & 0.467 & 0.459 & 0.504 & 0.521 \\
U K. & 0.609 & 0.565 & 0.552 & 0.459 & 0.447 \\
Japan & 0.592 & 0.525 & 0.547 & 0.538 & 0.514 \\
$\quad$ Other Industrial Countries & & & & & \\
Austria & 0.411 & 0.408 & 0.360 & 0.387 & 0.368 \\
Denmark & 0.639 & 0.499 & 0.387 & 0.375 & 0.404 \\
Netherlands & 0.333 & 0.223 & 0.267 & 0.177 & 0.172 \\
Norway & 0.555 & 0.506 & 0.349 & 0.296 & 0.293 \\
Sweden & 0.589 & 0.507 & 0.420 & 0.431 & 0.469 \\
Finland & 0.655 & 0.573 & 0.426 & 0.317 & 0.330 \\
Greece & 0.538 & 0.433 & 0.418 & 0.362 & 0.317 \\
Spain & 0.688 & 0.430 & 0.282 & 0.202 & 0.165 \\
Ireland & 0.488 & 0.235 & 0.294 & 0.341 & 0.299 \\
Australia & 0.372 & 0.294 & 0.144 & 0.131 & 0.187 \\
$\quad$ Developing Countries & & & & & \\
South Africa & 0.200 & 0.387 & 0.305 & 0.325 & 0.316 \\
Mexico & 0.722 & 0.722 & 0.537 & 0.576 & 0.459 \\
India & 0.713 & 0.667 & 0.473 & 0.492 & 0.447 \\
Indonesia & 0.390 & 0.350 & 0.271 & 0.266 & 0.265 \\
South Korea & 0.650 & 0.446 & 0.401 & 0.420 & 0.364 \\
Philippines & 0.479 & 0.434 & 0.415 & 0.462 & 0.330 \\
Pakistan & 0.390 & 0.249 & 0.218 & 0.246 & 0.185 \\
& & & & & \\
Standard Errors & 0.111 & 0.091 & 0.079 & 0.070 & 0.064
\end{tabular}


Table 6: Approximate Maximum Likelihood Estimates of the Fractional-Differencing Parameter $d$ for WPI-based Inflation Rates

$\begin{array}{lcccc}\text { Inflation Series } & \begin{array}{c}A R(p) \\ \text { Order }\end{array} & \begin{array}{c}\text { Long } \\ \text { Memory } \\ \text { Parameter }\end{array} & \begin{array}{c}\text { Standard } \\ \text { Error for } d \\ \text { Estimate }\end{array} & \begin{array}{c}\text { t-statistic } \\ \text { for } \\ H_{0}: d=0\end{array} \\ \text { G7 Countries } & 0 & 0.331 & 0.045 & 7.253 \\ \text { U.S. } & 1 & 0.560 & 0.066 & 8.451 \\ \text { Canada } & 0 & 0.550 & 0.050 & 10.822 \\ \text { Germany } & 0 & 0.479 & 0.044 & 10.898 \\ \text { U.K. } & 1 & 0.436 & 0.120 & 3.607 \\ \text { Japan } & & & & \\ \text { Other Industrial Countries } & 0 & 0.135 & 0.044 & 3.028 \\ \text { Austria } & 2 & 0.410 & 0.080 & 5.083 \\ \text { Denmark } & 1 & 0.315 & 0.061 & 5.149 \\ \text { Netherlands } & 1 & 0.362 & 0.062 & 5.812 \\ \text { Norway } & 1 & 0.255 & 0.098 & 2.603 \\ \text { Sweden } & 1 & 0.516 & 0.061 & 8.456 \\ \text { Finland } & 0 & 0.300 & 0.051 & 5.839 \\ \text { Greece } & 2 & 0.446 & 0.070 & 6.328 \\ \text { Spain } & 0 & 0.363 & 0.045 & 7.917 \\ \text { Ireland } & 2 & 0.403 & 0.064 & 6.254 \\ \text { Australia } & & & & \\ \text { Developing Countries } & 0 & 0.231 & 0.045 & 5.054 \\ \text { South Africa } & 0 & 0.465 & 0.043 & 10.610 \\ \text { Mexico } & 0 & 0.361 & 0.052 & 6.918 \\ \text { India } & 0.209 & 0.048 & 4.306 \\ \text { Indonesia } & 0.355 & 0.048 & 7.350 \\ \text { South Korea } & 0 & 0.322 & 0.049 & 6.504 \\ \text { Philippines } & 0.049 & 0.044 & 1.786 \\ \text { Pakistan } & 0 & & & \end{array}$

Note: The ML method is the frequency-domain approximate ML method proposed by Fox and Taqqu (1986). 